\title{
3 Stanislavsky: Guru and Villain
}

I have a great respect for Stanislavsky-for his insights into acting and for the techniques and approaches he devised. Years after my Stanislavsky-based training, I continue to use aspects of his Psycho-Technique, Method of Physical Actions and Active Analysis in both my acting and teaching. However, you can and probably should be critical of those you admire-and when it comes to the creativity of acting, Stanislavsky is both guru and villain.

It would be difficult to overlook how often Stanislavsky invokes the actor's creativeness. No other acting theorist or practitioner before or since has invoked 'creativeness' and 'creative' so frequently, or was so preoccupied with identifying the creativity of acting. Stanislavsky himself commented that his 'lifelong concern has been how to get ever closer to the so-called 'System', that is to get ever closer to the nature of creativity' (Carnicke, 2000). In My Life in Art, he asks whether 'there can be no system for the creation of inspiration or system for creation itself?'. The question is, of course, rhetorical: for Stanislavsky, there could be such a 'system'-a system for creative acting. Stanislavsky's need for such a system was not merely theoretical, but practical and pressing. According to Tortsov, Stanislavsky's alter ego in An Actor Prepares, the theatres were brimming with examples of bad acting: derivative, imitative, clichéd and mechanical. In order to rescue the art of acting and enable actors to lay claims to being true artists, it was imperative for Stanislavsky that they identify and acknowledge their creativity. In My Life in Art, he writes: '[c]raftsmanship teaches the actor how to walk on the stage and play', but 'true art must teach him how to awaken consciously his subconscious creative self for its superconscious organic creativeness'.

In his exhortations for a new, creative acting, one that would arouse the actor's 'subconscious creative self', Stanislavsky was not saying anything particularly new. As discussed in the previous chapter, Victorian theatre critic and theorist George Henry Lewes had already observed that 'good' actors draw upon their own 'inner' resources. Nor was Stanislavsky rocking any boats when he claims in An Actor Prepares that 'the fundamental aim of our art is the creation of this inner life of a human spirit and its expression in artistic form' and the actor 'must fit his own human qualities to the life of this other person, and pour into it all of his own soul'. The acting these statements gesture toward had already emerged in the nascent theories of nineteenth-century acting critics and commentators such as Lewes.

However, Stanislavsky did push the envelope. If late-nineteenth century actors had only just been called upon to identify with their characters, Stanislavsky asks them to go further: to bring together the inner lives of their characters and their own inner selves to the point where they are frequently conceived as indivisible. In Creating a Role he writes: 
a great deal that is in your part and a great deal that is in you have become so intertwined that you cannot easily distinguish where the actor begins or the character ends. When you are in that state you come closer and closer to your part, you feel it inside you and feel yourself inside it (Stanislavski, 1961).

To 'feel yourself inside it': this is the radical shift, marking a new ideal for the actorto get 'closer to the source of his inner life, his own nature as an actor, closer to that mysterious and intimate center which is the 'I' in a role' (Stanislavski, 1961). William Worthen makes the point that for Stanislavsky the 'committed and creative actor achieves an authentic sense of being through acting, the sense of 'I am' (Worthen, 1984). At this juncture, creativity and commitment come together in a fusion of selfdiscovery with its counterpart-self-revelation. In order to show that they have contacted the 'source' of their 'inner lives', actors must give the impression of self-revelation, creating the illusion of deeply felt sincerity and naturalness.

The progression is clear: while eighteenth-century acting can be defined as the skilful playing of the passions, and nineteenth-century acting the convincing portrayal of character, Stanislavsky gestures towards an acting which is revolutionary: acting as self-revelation. Lewes had already prioritized the actor's individual selfexpression, but Stanislavsky takes it one step further: through the prism of character, 'true', 'creative' actors reveal their own 'essential' beings. In Building a Character, Stanislavsky observes:

characterisation is the mask which hides the actor-individual. Protected by it he can bare his soul down to the last intimate detail. This is an important attribute or feature of characterisation (Stanislavski, 1977).

Given the times in which Stanislavsky practised and theorized, it is not difficult to understand why he would seek to promulgate a conception of acting as self-revelation: Naturalism emphasized 'real-life' depth and complexity of character and the Romantic ideal saw art as reflections of the soul. Worthen makes this point, noting that with a new emphasis on 'the powerful representation of dramatic character', acting moved closer to the ideals of Romanticism and Naturalism, but what pushed it over the line is the notion that it is somehow 'a dignified expression of the artist's identity' (Worthen, 1984).

Whatever Stanislavsky's reasons, this is our inheritance in the West: acting, as an art, is part character-creation and part self-revelation. The question of ratio is to this day a point of contention for theorists, intrigue for audiences and of practical concern for actors.

It is this concern that Stanislavsky's System aimed to address-and, in the process, achieve the radical: reveal a (the) blueprint of creative acting. If the most pressing issue confronting nineteenth-century acting theorists was to explain how the inner lives of actors and their characters could coalesce, then Stanislavsky showed how it was to be done. Stanislavsky established a methodology of unprecedented comprehensiveness 
for the actor's creative process, and although he was himself loathe to describe his System as definitive, aspects of it, particularly his psycho-technique, took root and continue to inform actors' creative processes. Had he just theorized, he may have receded into the shadows of theatre history, being of academic interest only, but his System-a detailed approach to acting by a respected actor with an insider's intimate knowledge-ensured his far-reaching attraction and influence. This is the reason Stanislavsky stands out, why Stan is guru for some.

\subsection{Stanislavsky: Redefining the Actor's Creativity}

But there is a flip side. Stanislavsky can also be cast as villain. As much as he extolled and promoted the creativity of acting, he simultaneously restricted the actor's authority and creativity in decisive ways.

Although it was not his main aim (and, therefore, often goes undetected), Stanislavsky defined not only the creative role of the actor but also what he saw as the other two major artists of the theatre: the writer and, more significantly, the director. If all their creative responsibilities were clearly defined and assigned, if each knew his or her place, this would facilitate, according to Stanislavsky in My Life in Art, the creation of a unified, well-integrated theatrical production:

What is important to me is that the collective creation of all the artists of the stage be whole and complete and all those who helped to make the performance might serve for the same creative goal and bring their creations to one common denominator (Stanislavsky, 1924/1952).

In Stanislavsky's ideal collaboration, the playwright produces the seminal work and it is the duty of the actor and director to bring this to fruition:

In the creative process there is the father, the author of the play; the mother, the actor pregnant with the part; and the child, the role to be born. [...] The director helps the process along as a sort of matchmaker (Stanislavsky, 1964).

Following his analogy, once authors have done the deed they are dispensable, and directors may be helpful, but are not essential. Ultimately, actors have the sole responsibility of 'giving birth' to the role. In this way Stanislavsky deemed the actor a creative artist, independent from both the writer and director. The creative independence of the actor was something that Stanislavsky obviously felt very passionately about. For example, when the student Grisha asks in An Actor Prepares, 'what is left for the actor since everything is prepared by others? Just trifles?' Tortsov is indignant:

Do you think that to believe in the imaginative fiction of another person, and to bring it to life, is a trifle? [...] We know of cases where a bad play has achieved world fame because of having been re-created by a great actor. [...] We bring to life what is hidden under the words; we put our 
own thoughts into the author's lines, and we establish our own relationships to other characters. [...] We filter through ourselves all the materials that we receive from the author and the director; we work over them, supplementing them out of our own imagination. [...] And as a final result we have truly productive activity. [...] And that tremendous work you tell me is just trifles! No, indeed. That is creativeness and art (Stanislavski, 1963).

Sharon Marie Carnicke is correct in claiming that Stanislavsky 'consistently demands respect for the actor as a creative artist, independent of the author who wrote the play, the designer who envisions it, and the director who stages it' (Carnicke, 1998). There is no doubt that Stanislavsky rated highly the independent creativity of the actor. However, he increasingly conceived of it as dependent on the director.

It cannot be overstressed that in Stanislavsky's day, directors were relative newcomers to the theatre. Cast as 'matchmaker', the director may seem indispensable, but writers and actors throughout most of theatre's history got along perfectly well without their services. Rudlin and Paul note that the 'ubiquity of the director in theatre and film is today as unquestioned as that of the sea captain: every ship must have one', but 'when Copeau became a director (metteur en scène) in 1913, 'the job had only been thought of as desirable, let alone necessary, for three decades or so' (Rudlin \& Paul, 1990). In order to secure their position in theatre production, directors needed to carve out their own creative role. Fabrizio Cruciani makes the point that the fledgling 'director-teachers' aimed 'not only to train students for the theatre, or for their own theatres, but also to forge the implements of their own creativity' (Cruciani, 1991). While the actor becomes the main 'implement' of the director's creativity, the actor's own creativity becomes increasingly dependent on the director, and the partnership of actor and director is forged as the most significant creative relationship in theatre: Stanislavsky and Olga Knipper, Brecht and Helene Weigel, Grotowski and Ryszard Cieślak are testimonies to this. The upshot: the actor-audience relationship is pre-empted.

The director assumed the role of spokesperson for the author and-as first spectator-also became spokesperson for the audience. 'Omniscient' and 'omnipresent', directors positioned themselves at both the beginning and end of the theatrical process, and increasingly actors came to rely on them to mediate: to assume primary responsibility for interpreting the text and for speculating on the spectators. Between text and actor, between audience and actor, the director is now the linchpin of theatre's creative processes, the point around which it now pivots. I definitely do not wish to argue a case for the dispensability of directors (I rather like them, and enjoy being one), but to make the point that Stanislavsky allocated increasing creative responsibilities to the director, ensuring not only his/her role in interpreting the text, creating the mise en scène, orchestrating ensemble playing-but also in the creative processes of the actor.

Stanislavsky's director is crucial to the actor. The director takes care of the big picture, taking care of things which might get in the way of actors achieving their main goal of creating characters. In Stanislavsky's own words, the director assumes 
responsibility for 'the expressiveness of the over-all performance' and its 'external shaping' (Stanislavski, 1968). This allows the actor to focus on the minutiae of characterisation. But Stanislavsky's job description for directors doesn't end here: the director 'must' also 'facilitate the creativeness of the actors' (Stanislavski, 1968). There are numerous ways in which a director can do this: as inspirational coach or muse, a 'talented director may come along and drop just a word, the actor will catch fire and his role will glow with all the colours of his soul's prism' (Stanislavski, 1977). The director also helps the actor keep on track, making sure that the role 'evolves naturally and only from the artistic kernel of the play' (Stanislavski, 1968). And, in one their most important roles, directors assist actors in the realisation of their characters: helping the actor, for example, 'break down the role into smaller units' and 'separate objectives' (Stanislavski, 1968). Under such direction, actors are nominally left free to concentrate on their characterisations. This, however, may prove less of a boon than it seems: as the creativity of acting is now taken up almost exclusively by charactercreation, actors become more and more reliant on directors, and arguably relinquish other facets of their creativity. In An Actor Prepares, Tortsov challenges the students:

Just try to stand up in such a space [an empty space] and pour out the role of Hamlet, Othello, Macbeth! How difficult is it to do without the help of a director, or scheme of movements, without properties that you can lean on (Stanislavski, 1963).

The actor's work has become 'difficult' without the director. Not that directors should, in Stanislavsky's opinion, foist themselves upon 'their' actors, showing 'them all the 'business", but they have become unquestionably integral to their actor's creativity: 'I have arrived at the conviction that the creative work of the director must proceed in unison with that of the actor' (Stanislavski, 1968).

\subsection{Rehearsals: Site of the Actor's Creativity?}

It is the creative collaboration of director and actor that becomes the most significant relationship in the theatrical enterprise-a collaboration which, however, does not occur on stage in performance, but, crucially, only in rehearsal. The rehearsal is, thus, established as the place where the 'real' creative work of the actor takes place and, consequently, performance becomes marginalized. Post-Stanislavsky, the preeminence of the rehearsal in theatrical production may seem 'normal': 'the rehearsal process' has become part of theatrical vernacular and practice, but the extensiveness and complexity of rehearsals are, it must be remembered, a relatively new phenomenon, one that Stanislavsky played a huge part in creating. At the Moscow Art Theatre of the late-1920s and early-1930s, the impact of this new phenomenon was evident. Actor Vasili Toporkov observes: 
During very intensive, very active rehearsal work, nobody gives any thought to the final result, that is, to the final performance; here the future audience is somehow ignored. [...] Much more attention is given to things which the audience will never see (Toporkov, 1954/1998).

Stanislavsky's attention was essentially on the actor in the rehearsal or classroom: the theories, methodologies and techniques are primarily all designed for these arenas. At the Opera-Dramatic Studio in Moscow (1935-1938), 'students spent almost two years studying before they were allowed to begin work on a play', let alone perform one for an audience-two years focused on developing the 'means by which to create and communicate the Dramatic 'I"' (Benedetti, 1998). Rehearsals, according to Stanislavsky in An Actor Prepares, should be as long as it takes for the character to reach 'full-term', that is, 'as long as that of a human being'. This is when and where the primary creation occurs.

It can be argued that Stanislavsky's psycho-techniques (relaxation of muscles, concentration of attention, faith and sense of truth, imagination, given circumstances, emotion memory and so forth) are aimed at enabling the actor in performance to induce the 'creative inner state' so that he or she can create anew night after night. Indeed, Stanislavsky recognized that in performance, the actor is not in some kind of creative stasis:

in our art you must live the part every moment that you are playing it, and every time. Each time it is recreated it must be lived afresh and incarnated afresh (Stanislavski, 1964).

But performance is not considered as being a site of creativity in its own right, one possibly requiring different skills to those needed in the rehearsal. Performance is, at most, when and where a prior creation is 'recreated'.

It is not difficult to understand why rehearsals should become a privileged site. For theorists and teachers of acting alike, it is much easier to put theories and methods to the test in the laboratory-like environment of the rehearsal and classroom, compared to which the performance situation, with its many variables, tends to frustrate analysis and elude control. Nor is it by accident that the rise of the modern director occurred alongside the rise of the rehearsal. After all, the director's primary creative realm is the rehearsal and beyond here, in performance, he or she is present only by proxy. Gnawing their fingernails to the quick, they are forced to scratch out a few meager, impotent notes and sit in excruciating silence and watch. For some this proves an impossible feat, one which Polish director Tadeusz Kantor got around by sometimes appearing as a 'player' in his productions. Thankfully, Kantor is an exception to the norm.

It must not be overlooked that at the time of formulating his theories and methods, Stanislavsky was primarily a director and teacher: although his work finds its impetus in his experiences as an actor, his success and renown are based on his work as director-teacher. In this role, he would naturally favour the domain in which he could most 
fully exercise his own creativity. But the unfortunate result is that it is in rehearsal where Stanislavsky conceives the actor's 'real', creative work to take place:

the actor's work begins with the search for the artistic kernel of the play. This he must transplant to his own soul and from that moment shall begin his creative process. [...] If it is to be a genuine, living process and result in the creation of a living, vivid, truly artistic image [...] much more time is necessary than is usually allowed. [...] That is why in our theatre we do not put on a production after some eight or ten rehearsals [...] but only after dozens of rehearsals which sometimes continue over a period of several months (Stanislavski, 1968).

With this emphasis on rehearsal, performance is occluded as a creative site for the actor. In An Actor Prepares the first year passes and the students have not yet performed a play for an audience, only exercises and scenes for colleagues and teachers. The assumption is clear: nothing significant can be learned-or taught-in or about performance. In fact, the performance situation is even considered perilous. Cast out of the safe, laboratory environment of the rehearsal, actors are stranded: 'left to act without direction' and what is more, they must cope with an insidious 'obstacle': the audience. Tortsov's advice to the student-actors could not be clearer:

You must first discover what the obstacles are, and learn to deal with them. [...] The most important one, as you know, is the abnormal circumstance of an actor's creative work-it must be done in public (Stanislavski, 1964).

As actors become preoccupied with character-identification, and retreat into their own inner worlds, the audience becomes a problematic aspect of the creative processes of acting. Even before Stanislavsky was warning actors about the potentially lethal lure of the audience, Lewes had voiced his concern: audiences disturb 'the artistic imagination of the actor by withdrawing it from its direct object', and frustrate the actor's attempts toward 'imaginatively identifying himself with the character' (Cole \& Chinoy, 1970). Following Lewes' lead, Tortsov is adamant:

'I hope you will take your minds off the audience';

'The magnet of the audience is to be resisted';

'Forget about the public. Think about yourself. [...] If you are interested, the public will follow you';

'There are still many actors [...] who in defiance of any illusion we can create, by means of light, sounds or colour still feel their interest more centred in the auditorium than on the stage';

'[T]he stage, with all its attendant publicity, tends to lead actors away from natural, human adaptations to situations, and tempts them to conventional, theatrical ways' (Stanislavski, 1964). 
In fact, psycho-techniques such as 'concentration of attention' and 'public solitude' are especially designed to mitigate the potentially disruptive influence of audiences, enabling the actor to retreat into him or herself 'like a snail in its shell' (Stanislavski, 1963).

One must, of course, contextualize Stanislavsky's circumspection regarding audiences. In the first instance, there was his own stage fright. He describes how exercises aimed at focusing in on himself helped him overcome performance anxiety and promote his creativity:

My public exercises centred my attention on the perceptions and states of my body, at the same time drawing my attention away from what was happening on the other side of the footlights, in the auditorium beyond the black and terrible hole of the proscenium arch. In what I was doing I ceased to be afraid of the audience, and at times forgot that I was on the stage. I noticed that it was especially at such times that my creative mood was most pleasant (Cole \& Chinoy, 1970).

Beyond this, Stanislavsky was also countering inherited and outdated acting conventions aimed gratuitously at wooing and wowing audiences. But over one hundred years later and removed from this context, one must be very careful about taking Stanislavsky literally. In the 1970s, Peter Handke may have offended his audience by direct insults, but for Australian director, Aubrey Mellor, the insult is now in a tendency to ignore the audience:

that whole respect-or need-for an audience has sort of disappeared. And if the public doesn't need to be there, what are we doing? I actually get really offended by theatre where I know that if I walked out it would have no effect on anyone on stage. It's like there's the 'old-fashioned' actor who likes performing, and the new actor who actually prefers the rehearsal room (Macaulay, 2003).

As a man of the theatre, and especially as an actor, Stanislavsky must have known that his fourth-wall, public-solitude acting is for the actor, as well as audiences, only an illusion. In An Actor Prepares, when the fictional student Paul argues that actors get nothing from audiences-only ‘[a]pplause and flowers', Tortsov counters:

What about laughter, tears, applause during the performance, hisses, excitement! Don't you count them? [...] The audience constitute the spiritual acoustics for us. They give back what they receive from us as living, human emotions (Stanislavski, 1964).

Tortsov even goes as far to suggest that an audience can inspire the actor's creativity: a 'crowd of spectators oppresses and terrifies an actor, but it also rouses his truly creative energy’. Advising novice actors, Stanislavsky is unequivocal:

take your places beside us in front of the footlights more often. The things I am talking about are not learned in the classroom, in rehearsals, or in working at home. They are learned principally in front of the footlights, before a full auditorium, heart to heart, in the very moment of creativeness (Stanislavski, 1968). 
What is learned 'in front of the footlights' is, however, never articulated. Unfortunately, Stanislavsky goes no further on the subject, falling short of even gesturing toward a methodology of actor/audience/performance. But it is the heart of the matter: performance is when and where the actor becomes the primary creator. Nicholas Arnold is apposite:

\begin{abstract}
Notwithstanding the control of preparation and reception by the director, the actor controls production. [...] It is not possible (except perhaps for Tadeusz Kantor) for directors to materialize on stage and polymorphically embody their internal Platonic interpretations. [...] A production is prepared under one set of circumstances. It is performed under another set, which varies nightto-night, moment-to-moment. The messages must, therefore, be continuously re-encoded, so that they are received in the desired way, under differing conditions. It is, of course, at this point that the performance 'realizes' itself, via the actor. Up to now, it has merely been a complex of well-founded conjectures, lacking the audience as the vital articulatory component (Arnold, 1991).
\end{abstract}

It is in performance that the actor has to embark on a new act of creation-with the audience as complicit and even co-creators. It is ironic, therefore, that while Stanislavsky championed the creativeness of the actor, to a great degree he actually curtailed it, occluding from the actor's repertoire the creative relationship of actor and audience. Masakazu makes the observation that when 'Stanislavski and his successors took the center stage, the audience was always treated as a subordinate factor in performance and was never regarded as an essential part of dramatic creation' (Masakazu, 1984). 'Never' may be too strong a word, but what is certain is that Stanislavsky privileged the creative processes of the rehearsal room. It was there, working with directors that the actor's 'true' creativity resided.

An actor's creativity, however, is not in actuality restricted to collaborating with directors in rehearsal rooms or, even, to character-creation: actors create more than characters and they do so in performances for audiences. Stanislavsky never ventured this far. Nor did his followers. Not the least bequest of Stanislavsky to Western theatre is to have drawn the line on the actor's creativity this side of performance. It is a line which remains firmly in place in actor-training, where Stanislavsky's legacy, combined with professional pedagogies, have served to establish a hegemonic-and restrictive-practice. 